\title{
Multistate Comparison of Attractants for Monitoring Drosophila suzukii (Diptera: Drosophilidae) in Blueberries and Caneberries
}

\author{
HANNAH J. BURRACK, ${ }^{1,2}$ MARK ASPLEN, ${ }^{3}$ LUZ BAHDER, ${ }^{4}$ JUDITH COLLINS, ${ }^{5}$ \\ FRANCIS A. DRUMMOND,${ }^{5}$ CHRISTELLE GUÉDOT, ${ }^{6}$ RUFUS ISAACS,${ }^{7}$ DONN JOHNSON,${ }^{8}$ \\ ANNA BLANTON,${ }^{9}$ JANA C. LEE ${ }^{10}$ GREGORY LOEB,${ }^{11}$ CESAR RODRIGUEZ-SAONA, ${ }^{12}$ \\ STEVEN VAN TIMMEREN,${ }^{7}$ DOUGLAS WALSH,${ }^{4}$ AND DOUGLAS R. MCPHIE ${ }^{1}$
}

Environ. Entomol. 44(3): 704-712 (2015); DOI: 10.1093/ee/nvv022

\begin{abstract}
Drosophila suzukii Matsumara, also referred to as the spotted wing drosophila, has recently expanded its global range with significant consequences for its primary host crops: blueberries, blackberries, raspberries, cherries, and strawberries. D. suzukii populations can increase quickly, and their infestation is difficult to predict and prevent. The development of effective tools to detect D. suzukii presence in new areas, to time the beginning of activity within a crop, to track seasonal activity patterns, and to gauge the effectiveness of management efforts has been a key research goal. We compared the efficiency, selectivity, and relationship to fruit infestation of a range of commonly used homemade baits and a synthetic formulated lure across a wide range of environments in 10 locations throughout the United States. Several homemade baits were more efficient than apple cider vinegar, a commonly used standard, and a commercially formulated lure was, in some configurations and environments, comparable with the most effective homemade attractant as well as potentially more selective. All alternative attractants also captured flies between 1 and 2 wk earlier than apple cider vinegar, and detected the presence of D. suzukii prior to the development of fruit infestation. Over half the Drosophila spp. flies captured in traps baited with any of the attractants were not $D$. suzukii, which may complicate their adoption by nonexpert users. The alternative $D$. suzukii attractants tested are improvement on apple cider vinegar and may be useful in the development of future synthetic lures.
\end{abstract}

KEY WORDS insect monitoring, fermentation bait, integrated pest management, invasive species

Drosophila suzukii Matsumura, also referred to as the spotted wing drosophila, has rapidly expanded its global range during the past $6 \mathrm{yr}$ and has been detected throughout the United States (Walsh et al. 2010, Burrack et al. 2012), Canada, Mexico, Europe (Cini et al. 2012), and South America (Depra et al. 2014).

\footnotetext{
${ }^{1}$ Department of Entomology, North Carolina State University, Campus Box 7634, Raleigh, NC 27695-7634.

${ }^{2}$ Corresponding author, e-mail: hjburrac@ncsu.edu.

${ }^{3}$ Natural Sciences Department, College of Arts and Sciences, Metropolitan State University, 700 East Seventh St., Saint Paul, MN, 55106.

${ }^{4}$ Department of Entomology, Washington State University, 24106 N. Bunn Rd., Prosser, WA 99350.

${ }^{5}$ School of Biology and Ecology, University of Maine, 305 Deering Hall, Orono, ME 04469.

${ }^{6}$ Department of Entomology, University of Wisconsin, 1630 Linden Dr., Madison, WI 53706.

${ }^{7}$ Department of Entomology, Michigan State University, 202 CIPS Bldg., East Lansing, MI 48824.

${ }^{8}$ Department of Entomology, University of Arkansas, 319 Agriculture Bldg., Fayetteville, AR 72701.

${ }^{9}$ Department of Entomology, University of Minnesota, 1980 Folwell Ave., St. Paul, MN 55108.

${ }^{10}$ USDA-ARS, Horticultural Crops Research Unit, $3420 \mathrm{NW}$ Orchard Ave., Corvallis, OR 97330.

${ }^{11}$ Department of Entomology, Cornell University, Geneva Experiment Station, Geneva, NY 14456.

${ }^{12}$ Department of Entomology, Rutgers University, 125 Lake Oswego Rd., Chatsworth, NJ 08019
}

This range expansion has been accompanied by significant losses in crop hosts of D. suzukii, including blueberries, caneberries, cherries, and strawberries (Bolda et al. 2010, Goodhue et al. 2011, Burrack et al. 2013). Because of zero tolerance for D. suzukii larvae in fresh marketed or whole processed fruit products, fruit producers have adopted intensive management programs, relying primarily on frequent insecticide applications, in an attempt to prevent infestation. Insecticide applications are typically initiated when fruit begin to ripen and becomes attractive to egg-laying D. suzukii and are continued on a schedule, often weekly, through the end of harvest (Haviland and Beers 2012, Van Timmeren and Isaacs 2013).

The introduction or reestablishment of schedule-based insecticide programs represents a significant shift from recent efforts to reduce insecticide-mediated impacts on nontarget organisms in fruit production (Roubos et al. 2014). Effective monitoring, either through direct observation of pest insects or through indirect methods such as trapping, is a cornerstone of integrated pest management, and monitoring strategies are often based on substantial knowledge of pest and host biology. Understanding the timing of D. suzukii activity and local population dynamics could help to improve management decisions and will be important to sustain integrated pest management programs in affected host crops. 
Table 1. Bait and lure treatments tested for trapping $D$. suzukii

\begin{tabular}{|c|c|c|c|}
\hline $\begin{array}{l}\text { Treatment } \\
\text { number }\end{array}$ & Treatment name & Components (per trap) & Source \\
\hline 1 & Apple cider vinegar & $150 \mathrm{ml}$ of apple cider vinegar, $0.16 \mathrm{ml}$ of unscented dish soap & Walsh et al. 2010 \\
\hline 2 & Yeast and sugar & $\begin{array}{l}1.69 \mathrm{~g} \text { of dry active yeast, } 8.45 \mathrm{~g} \text { of sugar, } 150 \mathrm{ml} \text { of water, } 0.16 \mathrm{ml} \text { of } \\
\text { unscented dish soap }\end{array}$ & Walsh et al. 2010 \\
\hline 3 & Fermenting bait cup & $\begin{array}{l}\text { Fermenting bait: } 25 \mathrm{ml} \text { of water, } 17.25 \mathrm{~g} \text { of whole wheat flour, } 2 \mathrm{~g} \text { of } \\
\text { sugar, } 1 \mathrm{ml} \text { of apple cider vinegar, } 0.325 \mathrm{~g} \text { of dry active yeast } \\
\text { Liquid bait: } 134 \mathrm{ml} \text { of apple cider vinegar, } 14.99 \mathrm{ml} \text { of } 95 \% \text { ethanol, } \\
0.74 \mathrm{ml} \text { of unscented dish soap }\end{array}$ & $\begin{array}{l}\text { R. Cowles and H. Faubert, } \\
\text { personal communication }\end{array}$ \\
\hline 4 & Droskidrink & $112 \mathrm{ml}$ of apple cider vinegar, $38 \mathrm{ml}$ of red wine, $3 \mathrm{~g}$ of Muscovado sugar & Grassi et al. 2014 \\
\hline 5 & $\begin{array}{l}\text { Synthetic lure over } \\
\text { apple cider vinegar }\end{array}$ & $\begin{array}{l}\text { Lures: TRE } 0890 \mathrm{~A} \text { and TRE } 0890 \mathrm{~B} \\
\text { Drowning solution: } 150 \mathrm{ml} \text { of apple cider vinegar, } 0.16 \mathrm{ml} \text { of } \\
\text { unscented dish soap }\end{array}$ & Trece Inc. (Adiar, OK) \\
\hline 6 & $\begin{array}{l}\text { Synthetic lure over } \\
\text { unscented } \\
\text { drowning solution }\end{array}$ & $\begin{array}{l}\text { Lures: TRE 0890A and TRE } 0890 \mathrm{~B} \\
\text { Drowning solution: } 150 \mathrm{ml} \text { of water, } 1.5 \mathrm{~g} \text { of Borax, } 0.06 \mathrm{ml} \text { of } \\
\text { unscented dish soap }\end{array}$ & Trece, Inc. (Adiar, OK) \\
\hline
\end{tabular}

A total of $150 \mathrm{ml}$ of each liquid was used per trap.

Invasive species, such as D. suzukii, represent substantial threats to commercial agriculture not only because they can aggressively spread and reach high populations (Sakai et al. 2001) and may be difficult to control with available management tools (Leskey et al. 2012, Bergmann and Raupp 2014). We often lack fundamental information on their biology necessary to effectively monitor their populations and to relate this information to damage risk. This is the case for D. suzukii, as growers of susceptible fruit crops currently lack effective monitoring tools that reliably detect the first presence of flies in a field, that track fly activity over time, or that reliably relate to larval densities in fruit. Detecting fly presence would be useful in determining when growers should begin insecticide applications, and tracking fly activity over time would aid in determining if fruit protection is needed and whether management programs are effective. Insect monitoring tools typically consist of a physical trap, such as a drowning solution or sticky matrix and are often augmented with attractants. These attractants may include colored stimuli, baits (food materials or approximations thereof), or lures (formulated or synthetic materials). Recent studies have addressed trap configuration as a means of increasing $D$. suzukii capture, using apple cider vinegar as a standard attractant (Lee et al. 2012, 2013). However, comparisons of alternative baits and volatiles produced by fermentation products show that apple cider vinegar is not the most efficient attractant (Cha et al. 2012, 2013; Landolt et al. 2012a,b; Iglesias et al. 2014). These previous bait or lure comparisons have been conducted over limited geographic areas, host crops, or duration. We compared efficiency, capture timing, and relation to fruit infestation for six candidate D. suzukii attractants. Attractants tested included both homemade baits and a synthetic lure that was under development at the time of our study, and is now commercially available (Trécé Inc., Adair, OK). In addition, we were also interested in assessing the reproductive status of female flies captured in different attractants because we anticipated that female fly orientation to food approximating lures may change as they transition to reproductive maturity, within reproductively immature flies that are more attracted to food lures and within reproductively mature flies that are more attracted to susceptible fruit. Comparisons were made over a wide geographic range and in several actively fruiting $D$. suzukii host crops to determine which were most appropriate for use across a broad range of environments.

\section{Materials and Methods}

Attractant Efficiency and Selectivity. We compared four noncommercial bait mixtures and two configurations of a commercially available four component synthetic lure (Table 1; hereafter referred to as the experimental treatments). Treatments were compared at 10 locations across 10 states (Table 2). The selected baits had been used in D. suzukii monitoring programs in the United States or Europe but had not been previously compared directly to one another. The synthetic lures were provided as numbered samples by Trécé Inc. (Adair, OK) and were based on a recently published four-component synthetic lure based on volatiles from rice vinegar and Merlot wine (Cha et al. 2012, 2013 , 2014). The lures are now available as part of a D. suzukii monitoring system marketed by Trécé Inc.

Treatments were compared over the course of at least $4 \mathrm{wk}$ at each location, $8 \mathrm{wk}$ at most locations (Table 2). Attractants were deployed in traps consisting of 946-ml clear plastic cups and solid lids with 10 holes evenly spaced near the top (DeliPRO brand, Tri-pack Industrial USA, White Plains, NY; described by Lee et al. 2012 as the "clear trap"). Traps were hung at the same level as fruit and placed prior to fruit ripening and present through harvest at each site. Within each location, each treatment was replicated four times in a randomized complete block design. Blocks were at least $10 \mathrm{~m}$ apart, and traps within a block were spaced between 3 and $10 \mathrm{~m}$ apart, depending on the dimensions of plantings within a location. Traps were serviced weekly and trap position was randomly rotated within each block to control for potential position effects. At each trap service, the liquid attractant was removed and replaced with freshly made liquid. The lures in 
Table 2. Sites, trapping period, and treatments in each state

\begin{tabular}{|c|c|c|c|c|}
\hline State & Crop(s) & Trapping period & Treatments present & Fruit infestation assessed? \\
\hline Arkansas & Blackberry (mixed varieties) & 13 June through 24 July & $1,2,3,4,5$, and 6 & Yes, 30 fruit per block \\
\hline Maine & Lowbush blueberry & 10 July through 27 Aug. & $1,2,3,4,5$, and 6 & No \\
\hline Michigan & Highbush blueberry & 24 July through 28 Aug. & $1,2,3,4,5$, and 6 & No \\
\hline Minnesota & Bunch grapes & 9 Sept. through 30 Sept. & $1,2,3,4,5,6$ & No \\
\hline New Jersey & Highbush blueberry & 12 June through 12 Aug. & $1,2,3,4,5$, and 6 & Yes, 30 fruit per block \\
\hline New York & Blueberry, raspberry, strawberry $^{a}$ & 30 May through 20 Aug. & $1,2,3,4$, and 5 & Yes, 30 fruit per block \\
\hline North Carolina & $\begin{array}{l}\text { Blackberry and raspberry } \\
\quad \text { (mixed variety planting) }\end{array}$ & 3 July through 22 Aug. & $1,2,3,4,5$, and 6 & Yes, 15-30 fruit per block as available ${ }^{b}$ \\
\hline Oregon & Highbush blueberry & 25 June through 12 Aug. & $1,2,3,4,5$, and 6 & Yes, 30 to 90 fruit per block ${ }^{c}$ \\
\hline Washington & Highbush blueberry & 18 June through 24 July & $1,2,3$, and 4 & No \\
\hline Wisconsin & Raspberry & 24 July through 11 Sept & $1,2,3,4,5$, and 6 & Yes, 30 fruit per block \\
\hline
\end{tabular}

A subset of the total sites assessed the rate of D. suzukii infestation in fruit simultaneous with trapping.

${ }^{a}$ No D. suzukii were captured at strawberry site, which was not included in analyses. Full treatment replications were conducted in each crop.

${ }^{b}$ Sample sized decreased when infestation reached $100 \%$ and fruit availability decreased.

${ }^{c}$ Sample size increased because of low infestation rate.

Treatments 5 and 6 were replaced biweekly, while the drowning solution was replaced weekly. Trap contents were transported back to the laboratory where the number of male and female D. suzukii (following Walsh et al. 2010), and the total number of nonD. suzukii Drosophilidae was enumerated using a stereomicroscope and recorded for each trap.

First D. suzukii Capture. The week during the experiment (1 to 8) when each trap first captured D. suzukii was recorded. Locations for which all traps captured flies during the first week of the experiment (Minnesota and Michigan) were excluded from this comparison, and only weeks during which the full complement of treatments was present at a site were considered. At some locations (New Jersey, New York, and Washington), the crop season began before the synthetic lures were available. Weeks preceding the use of the synthetic lures were excluded from analysis of week of first capture, and the first week when all the treatments were present was considered as Week 1 .

Fruit Infestation. A subset of locations assessed larval infestation in fruit. At these locations, a sample of undamaged fruit, ranging from 15 to 90 fruit was collected weekly from each block (Table 2). Fruit were held at $20^{\circ} \mathrm{C}$ in sealed, vented containers for at least 7 $\mathrm{d}$, after which the number of Drosophilidae larvae and pupae were recorded, and infestation rate (larvae per berry) was calculated. Sampling apparently undamaged fruit minimized the likelihood that non-D. suzukii larvae were present. Pupae collected from fruit were held until adult emergence to confirm species identification. Non-D. suzukii drosophilids were only reared from fruit in Wisconsin, and D. suzukii still represented $>90 \%$ of all flies reared from fruit at that location.

Reproductive Status of Captured Flies. For the first seven weeks of the experiment, a subsample of at least 10 randomly selected female $D$. suzukii from each trap at the North Carolina site, when available, were preserved in $70 \%$ ethanol and reserved for dissection to determine reproductive status. Up to 10 flies from each trap each week were dissected under a stereomicroscope (Olympus SZX10, Center Valley, PA). In cases when $<10$ female flies were captured in a given trap,

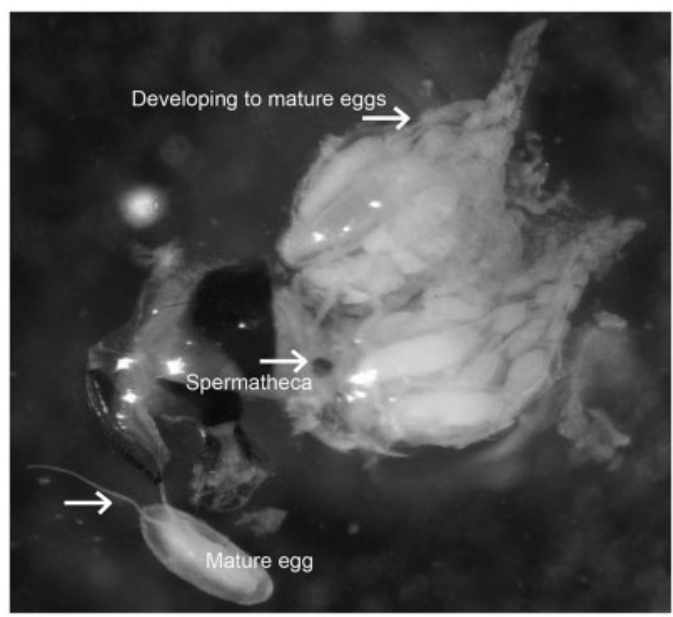

Fig. 1. Female D. suzukii reproductive system with ovaries containing developing to mature eggs.

all captured flies were dissected. The total number of mature eggs (those possessing fully formed respiratory filaments, Fig. 1) in both ovaries were counted, the ovarian development status ranked, and the spermathecae removed to assess mating status. Ovarian development rankings were 1) No eggs present and ovaries are small; 2) Only developing, immature eggs present; 3) Mature and immature eggs present; 4) Only mature eggs present. Spermathecae were crushed in a $2 \%$ aceto-orcein solution to allow for visualization of sperm, and female flies were considered mated or unmated based on the presence or absence of sperm.

Statistical Analyses. All data sets were screened to determine normality of residuals and homogeneity of variances via PROC GLM (SAS v. 9.3) using the Shapiro-Wilk test and Levene's test for equality of variances, respectively. Unless otherwise noted, analyses were conducted via PROC MIXED, and pairwise comparisons of the adjusted means were conducted using the Games-Howell adjustment to correct for multiple comparisons of data with unequal variances (via 
Table 3. Mean \pm SEM total, male, and female D. suzukii captures per week across all sites, in blueberry sites, and in caneberry sites

\begin{tabular}{lccc}
\hline \hline Treatment & All sites & & \\
\cline { 2 - 4 } & \multicolumn{1}{l}{ Total } & Male & Female \\
\hline Apple cider vinegar & $11.4 \pm 1.87 \mathrm{~d}$ & $3.8 \pm 0.68 \mathrm{c}$ & $7.6 \pm 1.29 \mathrm{c}$ \\
Yeast and sugar & $30.8 \pm 3.60 \mathrm{~b}$ & $8.3 \pm 0.88 \mathrm{~b}$ & $22.5 \pm 2.94 \mathrm{~b}$ \\
Fermenting bait cup & $104.3 \pm 14.78 \mathrm{a}$ & $26.5 \pm 3.65 \mathrm{a}$ & $77.8 \pm 11.91 \mathrm{a}$ \\
Droskidrink & $38.5 \pm 4.98 \mathrm{~b}$ & $10.2 \pm 1.28 \mathrm{~b}$ & $28.3 \pm 3.90 \mathrm{~b}$ \\
Synthetic lure over apple cider vinegar & $62.3 \pm 8.45 \mathrm{a}$ & $25.8 \pm 4.22 \mathrm{a}$ & $36.5 \pm 4.79 \mathrm{ab}$ \\
Synthetic lure over unscented drowning solution & $24.8 \pm 3.09 \mathrm{c}$ & $8.70 \pm 0.85 \mathrm{~b}$ & $16.1 \pm 2.52 \mathrm{c}$ \\
& & Blueberry sites & \\
Apple cider vinegar & $3.2 \pm 1.16 \mathrm{c}$ & $1.7 \pm 0.65 \mathrm{c}$ & $1.5 \pm 0.51 \mathrm{~b}$ \\
Yeast and sugar & $10.7 \pm 1.25 \mathrm{ab}$ & $5.0 \pm 0.70 \mathrm{~b}$ & $5.7 \pm 0.63 \mathrm{a}$ \\
Fermenting bait cup & $12.8 \pm 3.14 \mathrm{ab}$ & $7.1 \pm 1.91 \mathrm{~b}$ & $5.7 \pm 1.25 \mathrm{a}$ \\
Droskidrink & $8.2 \pm 1.25 \mathrm{~b}$ & $4.2 \pm 0.67 \mathrm{~b}$ & $4.0 \pm 0.62 \mathrm{a}$ \\
Synthetic lure over apple cider vinegar & $19.7 \pm 4.53 \mathrm{a}$ & $12.1 \pm 2.65 \mathrm{a}$ & $7.6 \pm 1.92 \mathrm{a}$ \\
Synthetic lure over unscented drowning solution & $11.8 \pm 1.55 \mathrm{ab}$ & $7.2 \pm 1.06 \mathrm{ab}$ & $4.6 \pm 0.56 \mathrm{a}$ \\
& & Caneberry sites & \\
Apple cider vinegar & $25.2 \pm 4.50 \mathrm{c}$ & $7.2 \pm 1.46 \mathrm{c}$ & $18.0 \pm 3.23 \mathrm{c}$ \\
Yeast and sugar & $63.9 \pm 8.91 \mathrm{~b}$ & $13.3 \pm 1.97 \mathrm{~b}$ & $50.6 \pm 7.39 \mathrm{~b}$ \\
Fermenting bait cup & $88.6 \pm 36.83 \mathrm{a}$ & $58.2 \pm 8.80 \mathrm{a}$ & $200.4 \pm 29.78 \mathrm{a}$ \\
Droskidrink & $142.1 \pm 21.36 \mathrm{~b}$ & $19.9 \pm 3.13 \mathrm{~b}$ & $68.9 \pm 9.70 \mathrm{~b}$ \\
Synthetic lure over apple cider vinegar & $49.6 \pm 11.09 \mathrm{a}$ & $92.6 \pm 12.00 \mathrm{~b}$ \\
Synthetic lure over unscented drowning solution & $47.4 \pm 7.63 \mathrm{c}$ & $11.5 \pm 1.60 \mathrm{c}$ & $36.0 \pm 6.41 \mathrm{c}$ \\
\hline
\end{tabular}

Values followed by the same letter are not significantly different $(\alpha=0.05)$.

lsmeans option ADJUST $=$ TUKEY ADJDFE $=$ ROW $)$. Because it was not possible to replicate all crops across all locations, we have limited our comparisons to those between crop only. We recognize that location may confound our interpretation of the data for crops, but comparisons of patterns within crops across locations suggested that crop effects were similar between states. For example, trap captures in blueberries were relatively lower than those in caneberries across locations, and females represented a larger proportion of captured flies in caneberries, regardless of location.

Fly capture data were log-transformed to meet the assumptions of normality, and the Satterthwaite approximation was used to calculate degrees of freedom due to heteroscedasticity. Week of experiment within each location and the interaction between treatment and week of experiment were included in initial trap capture analyses as a repeated, fixed effects, but the effect of week or its interaction with treatment were not significant for male, female, or combined D. suzukii captures. Therefore, week of experiment was considered a random variable for subsequent analyses of data that were collected over time. Within each location, block was also considered a random variable for all analyses. Several comparisons of trap capture data were made. First, data from all states were pooled to compare treatments across all crops and locations. For this analysis, block, week, and location were considered random effects. Next, to compare trap capture within crops, crop was included as a fixed variable in addition to treatment, while block and week were retained as random effects.

To compare selectivity among treatments, captures of D. suzukii were expressed as a proportion of all captured drosophilids, excluding instances when no D. suzukii were captured. Proportion data were arcsine square root-transformed to meet assumptions of normality, and the Satterthwaite approximation was used to calculate degrees of freedom due to heteroscedasticity. These data were then compared across states and within crops using the same effects as for trap captures.

Trap capture timing and relationship to fruit infestation were assessed in three ways. First, the week of first D. suzukii capture was compared across all locations with location as random variables. Second, the number of weeks each trap captured flies prior to fruit infestation detection was determined and compared both across states and within each state. Both values were also log-transformed prior to analysis to meet assumptions of normality. Because variances were acceptably homogeneous following transformation, the GamesHowell adjustment was not used for this analysis. Finally, linear regression analyses (PROC Reg, SAS v. 9.3) were conducted comparing trap captures of female D. suzukii for each treatment to the rate of fruit infestation, first pooling data for all participating locations, and second, for each location individually.

For the reproductive status data collected, mature egg counts were the most informative relative to treatment. Therefore, only analyses for this measure are presented. Mature egg counts (or egg load) were logtransformed to meet assumptions of normality, and were compared using treatment as a fixed effect, week as a repeated fixed effect, and block and individual fly as random effects.

\section{Results}

Bait and Lure Efficiency and Selectivity. Across all locations, the fermenting cup bait and the synthetic lure suspended over apple cider vinegar captured the 
Table 4. Mean \pm SEM total $D$. suzukii captures per week across within each participating state

\begin{tabular}{|c|c|c|c|c|c|}
\hline Treatment & Arkansas & Maine & Michigan & Minnesota & New Jersey \\
\hline Apple cider vinegar & $35.9 \pm 15.77 \mathrm{~b}$ & $0.52 \pm 0.33 \mathrm{~b}$ & $5.0 \pm 1.02 \mathrm{~b}$ & $5.0 \pm 2.15 \mathrm{c}$ & $10.7 \pm 6.64 \mathrm{~b}$ \\
\hline Yeast and sugar & $27.7 \pm 4.40 \mathrm{~b}$ & $5.7 \pm 1.73 \mathrm{a}$ & $20.1 \pm 3.39 \mathrm{a}$ & $27.3 \pm 10.18 \mathrm{ab}$ & $19.2 \pm 4.73 \mathrm{a}$ \\
\hline Fermenting bait cup & $137.8 \pm 34.64 \mathrm{a}$ & $3.7 \pm 1.24 \mathrm{ab}$ & $20.3 \pm 4.50 \mathrm{a}$ & $47.3 \pm 17.27 \mathrm{ab}$ & $34.5 \pm 17.02 \mathrm{a}$ \\
\hline Droskidrink & $65.9 \pm 15.28 \mathrm{a}$ & $1.3 \pm 0.45 \mathrm{ab}$ & $18.5 \pm 3.27 \mathrm{a}$ & $27.9 \pm 11.60 \mathrm{ab}$ & $20.2 \pm 5.73 \mathrm{a}$ \\
\hline Synthetic lure over apple cider vinegar & $203.9 \pm 71.80 \mathrm{a}$ & $3.0 \pm 0.78 \mathrm{ab}$ & $18.1 \pm 3.05 \mathrm{a}$ & $85.1 \pm 42.46 \mathrm{a}$ & $48.1 \pm 20.51 \mathrm{a}$ \\
\hline Synthetic lure over unscented drowning solution & $25.5 \pm 5.74 \mathrm{~b}$ & $1.1 \pm 0.37 \mathrm{ab}$ & $28.6 \pm 3.89 \mathrm{a}$ & $15.1 \pm 4.5 \mathrm{lbc}$ & $8.7 \pm 2.03 \mathrm{~b}$ \\
\hline Treatment & New York & North Carolina & Oregon & Washington & Wisconsin \\
\hline Apple cider vinegar & $1.9 \pm 0.54 \mathrm{a}$ & $53.3 \pm 14.61 \mathrm{c}$ & $1.9 \pm 0.65 b$ & $0.03 \pm 0.03 \mathrm{a}$ & $33.9 \pm 6.79 \mathrm{c}$ \\
\hline Yeast and sugar & $5.4 \pm 1.15 \mathrm{a}$ & $151.3 \pm 28.08 b$ & $18.6 \pm 3.36 \mathrm{a}$ & $0.03 \pm 0.03 \mathrm{a}$ & $110.0 \pm 16.35 b$ \\
\hline Fermenting bait cup & $7.0 \pm 1.46 \mathrm{a}$ & $651.5 \pm 106.59 \mathrm{a}$ & $18.8 \pm 4.10 \mathrm{a}$ & $0.15 \pm 0.06 \mathrm{a}$ & $402.2 \pm 79.10 \mathrm{a}$ \\
\hline Droskidrink & $3.5 \pm 0.71 \mathrm{a}$ & $182.5 \pm 28.60 \mathrm{~b}$ & $12.3 \pm 2.95 \mathrm{a}$ & $0.10 \pm 0.05 \mathrm{a}$ & $173.9 \pm 29.12 \mathrm{ab}$ \\
\hline Synthetic lure over apple cider vinegar & $10.1 \pm 2.14 \mathrm{a}$ & $114.5 \pm 25.77 \mathrm{~b}$ & $24.4 \pm 4.97 \mathrm{a}$ & $0.25 \pm 0.13 \mathrm{a}$ & $130.8 \pm 20.30 \mathrm{~b}$ \\
\hline Synthetic lure over unscented drowning solution & - & $19.3 \pm 4.34 \mathrm{~d}$ & $18.2 \pm 4.18 \mathrm{a}$ & $0.08 \pm 0.08 \mathrm{a}$ & $89.3 \pm 16.90 \mathrm{~b}$ \\
\hline
\end{tabular}

Values within a state followed by the same letter are not significantly different $(\alpha=0.05)$.

Table 5. Trap selectivity, expressed as D. suzukii captures as a proportion of total Drosophilidae (nontarget and $D$. suzukii combined) captured per trap per week

\begin{tabular}{llll}
\hline \hline Treatment & All sites & Blueberries & Caneberries \\
\hline Apple cider vinegar & $0.4 \pm 0.02 \mathrm{~b}$ & $0.2 \pm 0.03 \mathrm{~b}$ & $0.6 \pm 0.03 \mathrm{ab}$ \\
Yeast and sugar & $0.4 \pm 0.02 \mathrm{~b}$ & $0.2 \pm 0.02 \mathrm{~b}$ & $0.6 \pm 0.03 \mathrm{a}$ \\
Fermenting bait cup & $0.2 \pm 0.02 \mathrm{c}$ & $0.1 \pm 0.01 \mathrm{c}$ & $0.4 \pm 0.03 \mathrm{~d}$ \\
Droskidrink & $0.3 \pm 0.02 \mathrm{~b}$ & $0.2 \pm 0.02 \mathrm{~b}$ & $0.5 \pm 0.03 \mathrm{bc}$ \\
Synthetic lure over apple cider vinegar & $0.3 \pm 0.02 \mathrm{c}$ & $0.2 \pm 0.02 \mathrm{bc}$ & $0.4 \pm 0.03 \mathrm{~cd}$ \\
Synthetic lure over unscented drowning solution & $0.5 \pm 0.02 \mathrm{a}$ & $0.4 \pm 0.04 \mathrm{a}$ & $0.6 \pm 0.03 \mathrm{a}$ \\
\hline
\end{tabular}

Values followed by the same letter are not significantly different $(\alpha=0.05)$.

most total $D$. suzukii flies $(F=89.75 ; \mathrm{df}=5,1937$; $P<0.0001)$ and male flies $(F=69.88 ; \mathrm{df}=5,1937$; $P<0.0001$; Table 3$)$. The fermenting cup bait captured the most female flies, while the synthetic lure suspended over apple cider vinegar captured a similar number of females to the yeast and sugar and the Droskidrink baits $(F=79.35 ; \mathrm{df}=5,1937 ; P<0.0001$; Table 3).

The interaction between crop and treatment was significant for total $(F=16.41 ; \quad \mathrm{df}=10 ; \quad 1962$, $P<0.0001), \quad$ male $\quad(F=13.64 ; \quad \mathrm{df}=10, \quad 1962$; $P<0.0001)$, and female $(F=18.43 ; \mathrm{df}=10,1962$; $P<0.0001)$ D. suzukii captures across all states, with lower trap captures and fewer differences between treatments in blueberries and higher fly captures in caneberries (Table 3). In blueberries, apple cider vinegar-baited traps caught fewer flies relative to all other treatments and had similar trap captures to the synthetic lure over an unscented solution. This trend was similar within each state as well, with apple cider vinegar generally capturing the fewest flies, although it occasionally exceeded the synthetic lure over an unscented solution (Table 4; treatment $\times$ state: $F=15.26 ; \mathrm{df}=44,1929 ; P<0.0001)$.

While treatments did differ significantly in the proportion of drosophilids that were D. suzukii across all states and within crops (treatment: $F=71.96 ; \mathrm{df}=5$, 1115; $P<0.0001$; crop $\times$ treatment: $F=6.18$; $\mathrm{df}=10$, 1103; $P<0.0001$ ), at most $60 \%$ of the drosophilds
Table 6. First captures of $D$. suzukii, based on the number of weeks, flies were captured after trap placement

\begin{tabular}{ll}
\hline \hline Treatment & All sites \\
\hline Apple cider vinegar & $3.6 \mathrm{a}$ \\
Yeast and sugar & $2.2 \mathrm{~b}$ \\
Fermenting bait cup & $2.0 \mathrm{~b}$ \\
Droskidrink & $2.4 \mathrm{~b}$ \\
Synthetic lure over apple cider vinegar & $2.6 \mathrm{~b}$ \\
Synthetic lure over unscented drowning solution & $2.5 \mathrm{~b}$ \\
\hline
\end{tabular}

Values followed by the same letter are not significantly different $(\alpha=0.05)$. There was no significant difference in week of first capture between crops.

present in a trap were D. suzukii (Table 5). Across all crops, treatments with lower trap captures, notably the synthetic lure suspended over an unscented solution, generally captured a higher proportion of D. suzukii. The converse was also true; treatments that captured larger numbers of $D$. suzukii, such as the fermenting cup bait and synthetic lure suspended over apple cider vinegar, also captured a higher proportion of nontarget drosophilids. A greater proportion of the drosophilids captured in caneberries were D. suzukii than in blueberries (Table 5 ).

First D. suzukii Capture. There were no significant effects of crop $(F=3.91 ; \mathrm{df}=1,5 ; P=0.1051)$ or the interaction between crop and treatment $(F=0.95$; $\mathrm{df}=5,133 ; P=0.4520)$ on timing of first $D$. suzukii 
Table 7. Mean \pm SEM number of weeks by which positive $D$. suzukii trap captures predated fruit infestation

\begin{tabular}{|c|c|c|c|c|c|c|c|}
\hline Treatment & $\begin{array}{l}\text { All states with } \\
\text { fruit infestation }\end{array}$ & $\begin{array}{l}\text { Arkansas } \\
\text { (blackberry) }\end{array}$ & $\begin{array}{l}\text { New Jersey } \\
\text { (blueberry) }\end{array}$ & $\begin{array}{l}\text { New York } \\
\text { (blueberry) }\end{array}$ & $\begin{array}{l}\text { North Carolina } \\
\text { (blackberry and } \\
\text { raspberry) }\end{array}$ & $\begin{array}{l}\text { Oregon } \\
\text { (blueberry) }\end{array}$ & $\begin{array}{l}\text { Wisconsin } \\
\text { (raspberry) }\end{array}$ \\
\hline Apple cider vinegar & & & $0.0 \pm 0.41 \mathrm{a}$ & $-0.3 \pm 0.48 a$ & $-1.0 \pm 0.00 \mathrm{a}$ & $3.3 \pm 2.03 \mathrm{a}$ & $-1.5 \pm 0.50 \mathrm{a}$ \\
\hline Yeast and $s$ & $1.3 \pm 0.38 b$ & $1.0 \pm 0.00 \mathrm{a}$ & $1.3 \pm 0.48 \mathrm{ab}$ & $0.8 \pm 0.48 \mathrm{a}$ & $0.25 \mathrm{~b}$ & $5.0 \pm 1.53 \mathrm{a}$ & $-0.3 \pm 0.25 b$ \\
\hline Fermenting bait cup & $1.6 \pm 0.39 b$ & $1.0 \pm 0.00 \mathrm{a}$ & $2.5 \pm 0.87 \mathrm{~b}$ & $1.0 \pm 0.00 \mathrm{a}$ & $1.0 \pm 0.00 \mathrm{~b}$ & $5.0 \pm 1.53 \mathrm{a}$ & $0.0 \pm 0.00 \mathrm{~b}$ \\
\hline Droskidrink & $1.2 \pm 0.33 b$ & $1.0 \pm 0.00 \mathrm{a}$ & $2.0 \pm 0.91 b$ & $0.3 \pm 0.48 \mathrm{a}$ & $0.8 \pm 0.25 b$ & $4.0 \pm 1.00 \mathrm{a}$ & $0.0 \pm 0.00 \mathrm{~b}$ \\
\hline $\begin{array}{l}\text { Synthetic lure over apple } \\
\text { cider vinegar }\end{array}$ & $1.2 \pm 0.31 b$ & $1.0 \pm 0.00 \mathrm{a}$ & $1.3 \pm 0.63 \mathrm{ab}$ & $0.8 \pm 0.63 a$ & $1.0 \pm 0.00 \mathrm{~b}$ & $4.0 \pm 1.00 \mathrm{a}$ & $-0.3 \pm 0.25 b$ \\
\hline $\begin{array}{l}\text { Synthetic lure over unscented } \\
\text { drowning solution }\end{array}$ & $1.4 \pm 0.43 b$ & $1.0 \pm 0.00 \mathrm{a}$ & $1.5 \pm 0.65 \mathrm{ab}$ & - & $1.0 \pm 0.00 \mathrm{~b}$ & $7.7 \pm 1.45 \mathrm{a}$ & $-0.3 \pm 0.25 b$ \\
\hline
\end{tabular}

Negative values indicate that fruit infestation occurred prior to positive D. suzukii trap capture. Values followed by the same letter are not significantly different $(\alpha=0.05)$.

Table 8. Fit statistics $\left(R^{2}\right)$ for statistically significant $(\alpha=0.05)$ linear regressions of female trap captures and fruit infestation rate (larvae per berry)

\begin{tabular}{|c|c|c|c|c|c|c|c|}
\hline Treatment & $\begin{array}{l}\text { All states with } \\
\text { fruit infestation }\end{array}$ & $\begin{array}{l}\text { Arkansas } \\
\text { (blackberry) }\end{array}$ & $\begin{array}{l}\text { New Jersey } \\
\text { (blueberry) }\end{array}$ & $\begin{array}{l}\text { New York } \\
\text { (blueberry) }\end{array}$ & $\begin{array}{l}\text { North Carolina } \\
\text { (blackberry and } \\
\text { raspberry }\end{array}$ & $\begin{array}{l}\text { Oregon } \\
\text { (blueberry) }\end{array}$ & $\begin{array}{l}\text { Wisconsin } \\
\text { (raspberry) }\end{array}$ \\
\hline Apple cider vinegar & 0.0662 & ns & ns & 0.7500 & ns & ns & 0.1352 \\
\hline Yeast and sugar & 0.2229 & ns & 0.1955 & 0.3635 & 0.1420 & ns & 0.1430 \\
\hline Fermenting bait cup & 0.0813 & $\mathrm{~ns}$ & ns & ns & ns & ns & ns \\
\hline Droskidrink & 0.1272 & ns & 0.2262 & ns & $\mathrm{ns}$ & ns & ns \\
\hline $\begin{array}{l}\text { Synthetic lure over apple cider } \\
\text { vinegar }\end{array}$ & 0.1135 & ns & ns & 0.4616 & $\mathrm{~ns}$ & ns & 0.1745 \\
\hline $\begin{array}{l}\text { Synthetic lure over unscented } \\
\text { drowning solution }\end{array}$ & 0.5036 & ns & ns & - & $\mathrm{ns}$ & ns & 0.5179 \\
\hline
\end{tabular}

ns, not significant.

capture. Therefore, treatment was retained as the only fixed effect in the model $(F=12.47 ; \mathrm{df}=5,138$; $P<0.0001$ ), and apple cider vinegar-baited traps captured flies significantly later than all other treatments (Table 6).

Fruit Infestation. When states with fruit infestation data were pooled, all treatments except apple cider vinegar captured flies at least one week before fruit infestation was observed (treatment: $F=20.66$, $\mathrm{df}=5,106, P<0.0001$; state $\times$ treatment: $F=1.86$, $\mathrm{df}=24,82, P=0.021$; Table 7). However, observations within each state varied. There was no difference in the timing of captures relative to first infestation in Arkansas, New York, and Oregon locations, but these locations also had relative low infestation rates, averaging $0.87,0.62$, and $0.04 \mathrm{D}$. suzukii per berry, respectively (data not shown). North Carolina and Wisconsin had the highest infestation rates, with averages of 10.24 and 15.81 larvae per berry. Captures of female D. suzukii were generally poor predictors of fruit infestation rate within individual locations (Table 8). Captures in the yeast and sugar bait were most frequently predictive of fruit infestation rate, with significant correlations at four of the six individual locations. When data from all locations and crops were pooled, trap captures in all attractants were related to fruit infestation (Table 8). For most of the attractants, the relationship between trap captures and fruit infestation was weak, with the synthetic lure suspended over an unscented solution having the strongest relation$\operatorname{ship}\left(R^{2}=0.5036\right)$ across all sites.
Reproductive Status. Mature eggs possess two long respiratory filaments and were readily distinguishable from developing eggs (Fig. 1). There was a significant effect of the interaction between sample week and treatment on egg load $(F=2.45 ; \quad \mathrm{df}=28, \quad 1011$; $P<0.0001)$ at the North Carolina site. In general, captured female flies had higher egg load during the first week of trapping, prior to ripe fruit becoming abundant, with the notable exception of those captured with the synthetic lure suspended over an unscented solution (Fig. 2). Fruit began to ripen during the second week of trapping, after which egg load decreased across most treatments.

\section{Discussion}

The majority of the attractants we compared captured more D. suzukii earlier in the monitoring period than apple cider vinegar, a previous standard attractant. These attractants may be useful in a monitoring program designed to time the initiation of D. suzukii management, a valuable improvement over apple cider vinegar. The fermenting cup bait and synthetic lure over apple cider vinegar captured the most flies across all locations, and of these two attractants, the synthetic lure over apple cider vinegar was far easier to use. This attractant would be an appropriate choice for users interested in timing the initiation of $D$. suzukii treatments to fly activity and who are comfortable with fly identification. The yeast and sugar bait was significantly 

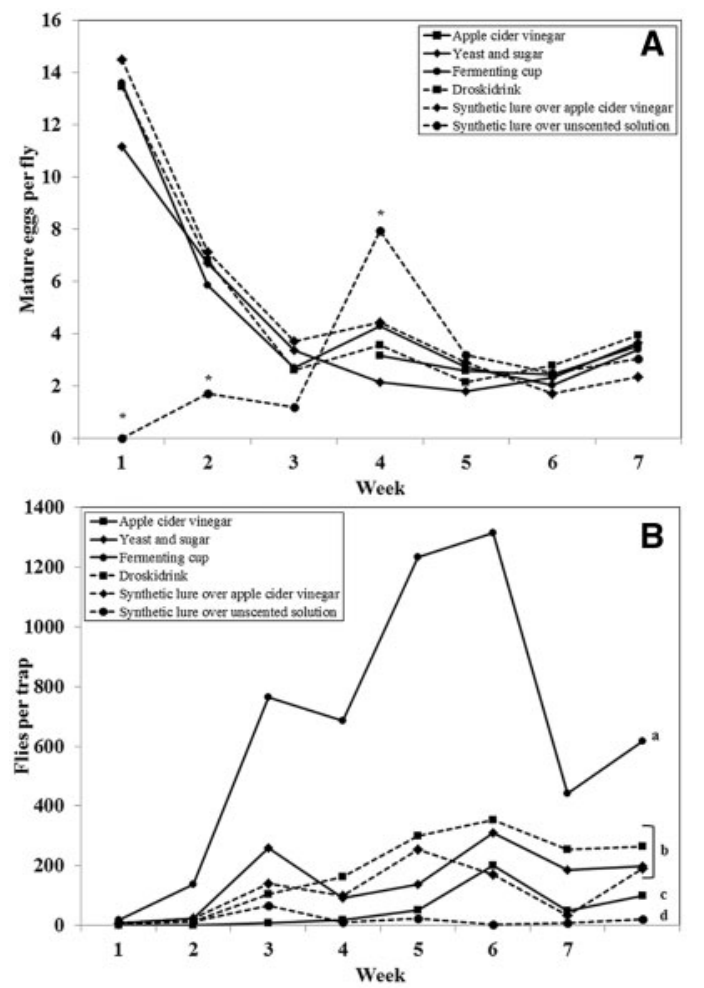

Fig. 2. (A) Mean egg load per female D. suzukii in each treatment Treatment. Values indicated by * are significantly different from other treatments (location $\times$ treatment: $\alpha=0.05$ ). (B) D. suzukii trap captures for each attractants at the North Carolina monitoring location. Lines indicated by the same letter are not significantly different $(\alpha=0.05)$.

correlated to fruit infestation at the most individual sites, but this correlation was still weak. The synthetic lure suspended over an unscented solution was more variable in total D. suzukii captures, but was most closely related to the rate of fruit infestation than other attractants across all sites. A larger sample size was likely necessary to detect the positive relationship between trap captures in the synthetic lure over an unscented solution because this treatment generally had low trap captures within individual sites.

We also identified significant constraints that may render our tested attractants less useful in tracking population dynamics of D. suzukii over the course of a season or for use in determining whether a management program has been effective. Specifically, no attractant was highly selective for D. suzukii in comparison with other Drosophilidae, and captures in any of the attractants were not consistently or strongly related to fruit infestation dynamics.

Attractant selectivity is important for ease of stakeholder use to limit impacts on nontarget organisms, and to reduce degradation of specimens in traps (Weber and Ferro 1991). The degree and importance of trap selectivity for a target pest varies between insects and based on intended use. For example, dogwood borers [Syanthedon scitula (Harris)] represented between 21 and $86 \%$ of the clearwing moths captured by the most selective pheromones tested by Bergh, et al. (2004). Historically, fall armyworm [Spodoptera frugiperda (J.E. Smith)] captures by pheromone-baited traps in Connecticut sweet corn ranged from 14 to $52 \%$ of all insects captured, but were 81 to $97 \%$ of all moths captured (Adams et al. 1989). More recently, nontarget moths have exceeded fall armyworm captures in pheromone traps in Pennsylvania (Fleischer et al. 2005). Issues associated with nontarget drosophila bi catch in D. suzukii traps are more similar to the case of nontarget moths in fall armyworm traps. Dogwood borers can be readily distinguished from the nontarget moths also present in traps, while fall armyworm moths require more careful, microscopic examination (Fleischer et al. 2005). Female D. suzukii also cannot be reliably distinguished from other drosophilids with the naked eye. While males may be easier to identify, nonpest drosophilids captured in traps may include species with wing spots or patterns, such as Chytomyza amoena (Loew), Leucophenga varia (Walker), and Scaptomyza spp. (Demchak et al. 2012), also confounding identification. D. suzukii identification is, therefore, challenging for nonexperts and time-consuming even for expert observers. As low a proportion of nontarget drosophilids as possible would, therefore, be desirable for D. suzukii monitoring traps. Although given that the materials compared are attractive by mimicking potential food sources, they are not likely to be as selective as species-specific sex lures. Of the attractants tested, the synthetic lure over unscented solution may be a compromise between attraction and selectivity, capturing generally fewer flies but a larger proportion of $D$. suzukii earlier than apple cider vinegar and with a stronger relationship to fruit infestation. It is noteworthy, however, that this attractant captures very low numbers of flies at some of the location (New Jersey and North Carolina, see Fig. 2B).

We did not identify nontarget drosophilids to species, so we cannot determine if nontarget captures differed in species composition among treatments, locations, or crops. This information would be useful in assisting stakeholders in distinguishing between the most likely nontarget species, and future optimization of traps, baits, and lures should address nontarget Drosophila species composition.

The weak relationships found between in-week adult trap captures and larval fruit infestation rates also complicate use by growers or other stakeholders. It is worth noting that the simple linear regressions we conducted may be improved by incorporating temporal lag between fly capture and fruit infestation, but stakeholders are often most interested in monitoring tools that can be related to proximate outcomes or trigger responsive action. The smallest fruit sample size at any location was 15 berries. Therefore, these samples would, at worst, be sensitive enough to detect a $6.67 \%$ infestation rate, assuming a truly random sample, a random infestation pattern, and high accuracy of samplers. There is currently zero tolerance for D. suzukii presence in fruit, and growers or marketers of fresh fruit would likely require a more accurate sampling method. 
We cannot determine from our data how trap captures would relate to infestation, as observed in larger sample sizes, necessary to detect D. suzukii in commercially marketed fruit.

An additional potential constraint is the cumbersome nature of several of the attractants we tested. In particular, while it was among the most attractive treatments, the fermenting bait treatment required two containers and a larger number of ingredients. With respect to ease of use within traps, the synthetic lures were far simpler to handle than homemade baits. They were also changed less frequently in our experiment (biweekly), and the current manufacturer recommendation is to change the lures monthly.

A key focus of our experimental design was to compare attractants in the period immediately preceding and during the harvest period, which is when D. suzukii management actions are targeted. This allowed us to assess relative attraction and efficiency under conditions in which our treatments were in competition with fruit. In general, D. suzukii trap captures increased over the course of the experiment within sites, which coincided with fruit ripening. However, the lack of significant interaction effects between time and treatments both within and between crops suggests that this increase in trap captures was uniform across treatments (North Carolina data illustrated in Fig. 2B), indicating that one treatment was not necessarily more competitive with host fruit than another. While the bait treatments do not appear to have differed in relative attraction with respect to crop phenology, the reproductive status of females attracted to traps, at least at the North Carolina site, did change over time. Prior to the availability of ripe fruit, females captured in most of the treatments had higher egg load than those captured in following weeks, suggesting that D. suzukii may mature eggs, irrespective of host availability or that flies were migrating into our planting from other host crops. A notable exception to this observation were flies captured in traps containing the synthetic lure over an unscented solution, which had lower egg load in the first $2 \mathrm{wk}$ of the experiment and higher egg load in the subsequent weeks. The general reduction in egg load in captured female D. suzukii may be because of the differential attraction between traps and fruit, with reproductively mature females more likely to orient toward fruit in which to lay eggs than to traps emitting fermentation volatiles, assumed to be food attractants for insects (Utrio and Eriksson 1977). Alternatively, we may have observed differences in egg load over time because of, first, accumulation, as flies stored eggs in advance of host availability, and then because of depletion, as females began to lay eggs in suitable hosts.

There were also interesting differences in the response to attractants in blueberry and caneberry sites. These differences cannot be entirely disentangled from geography, as sites were generally located in one crop within a state, but results are consistent across states. Trap captures in caneberries (blackberries and raspberries) were higher than those in blueberries. These differences could be owing to a range of factors, including, 1) phenology: caneberries may fruit later than blueberries; 2) host preference: caneberries are preferred over blueberries in choice and no choice scenarios (Lee et al. 2011, Bellamy et al. 2013, Burrack et al. 2013); 3) the surrounding habitat: availability of noncrop hosts may differ in blueberry and caneberry plantings; and 4) plant architecture: caneberries plants can be grown densely within trellises, while blueberry architecture is highly variable depending upon species. The most attractive treatments also differed between host crops, with the fermenting cup treatment outperforming the synthetic lure over apple cider vinegar in caneberries but not in blueberries. It may be possible that the larger fly captures in caneberries facilitated greater differentiation between treatments or that environmental or host specific factors influenced attraction.

Previous studies have addressed D. suzukii trap design (Lee et al. 2012, 2013; Iglesias et al. 2014) using apple cider vinegar as a standard lure. Trap design is an important factor, but the attractant is a key component of an effective trap. Optimization of traps to best take advantage of attractants that capture more flies earlier than apple cider vinegar is an important focus of future efforts. To be useful for effectively timing the initiation of D. suzukii management, traps should ideally be capable of detecting $D$. suzukii $>1 \mathrm{wk}$ before infestation develops, as development time of an egg to adult is typically between 10 and $14 \mathrm{~d}$, depending on host and temperature (Tochen et al. 2014). A number of the attractants we tested achieved this goal and, therefore, improved upon previous standards.

A protocol similar to this study is recommended for making a cohesive assessment of future attractants developed for D. suzukii. These attractants should be compared over a large range of climates, crops, and regions in sites with fruit present during the period of crop maturity (ripening and harvest) when growers make D. suzukii management decisions.

\section{Acknowledgments}

We thank Robert Holdcraft, Bridget Blood, Alison Denelsbeck, Jennifer Frake, Christina Fieland, Jesse Mindolovich, Tressa Franzmeier, Chris Pontius, Barbara Lewis, and Taunya Ernst for field and laboratory assistance. Funding was provided by the U.S. Department of Agriculture Specialty Crop Research Initiative (USDA SCRI) grant 2010-51181-21167, U.S. Department of Agriculture Current Research Information System (USDA CRIS) 5358-22000-037-00D, USDA/ Agricultural Marketing Service (AMS)/Arkansas Agriculture Department SCRI Grant 12-25-B-1214, USDA/National Institute of Food and Agriculture (NIFA)/University of Arkansas EIPM Coordination Program Grant. We are grateful to the fruit growers that allowed us to set up our experiments on their farms.

\section{References Cited}

Bellamy, D. E., M. S. Sisterson, and S. S. Walse. 2013. Quantifying host potentials: indexing post-harvest fruits for spotted wing drosophila, Drosophila suzukii. PLoS ONE 8: e61227.

Bergh, J. C., T. C. Leskey, and A. Zhang. 2004. Discrimination by male dogwood borer, Synanthedon scitula 
(Lepidoptera: Sesiidae), among traps baited with commercially available pheromone lures. J. Econ. Entomol. 97: $344-352$.

Bergmann, E. J., and M. J. Raupp. 2014. Efficacies of common ready to use insecticides against Halymorpha halys (Hemiptera: Pentatomidae). Fla. Entomol. 97: 791-800.

Bolda, M. P., R. E. Goodhue, and F. G. Zalom. 2010. Spotted wing drosophila: potential economic impact of a newly established pest. Agricultural and Resource Economics Update, University of California, Giannini Foundation, 13.

Burrack, H. J., J. P. Smith, D. Pfeiffer, G. Koehler, and J. LaForest. 2012. Using volunteer-base networks to track Drosophila suzukii (Diptera: Drosophilidae) an invasive pest of fruit crops. J. Integr. Pest Manage. 3: B1-B5.

Burrack, H. J., G. E. Fernandez, T. Spivey, and D. A Kraus. 2013. Variation in selection and utilization of host crops in the field and laboratory by Drosophila suzukii Matsumara (Diptera: Drosophilidae), an invasive frugivore. Pest Manage. Sci. 69: 1173-1180.

Cha, D. H., T. Adams, H. Rogg, and P. J. Landolt. 2012. Identification and field evaluation of fermentation volatiles from wine and vinegar that mediate attraction of spotted wing drosophila, Drosophila suzukii. J. Chem. Ecol. 38: 1419-1431.

Cha, D. H., S. P. Hesler, R. S. Cowles, H. Vogt, G. M. Loeb, and P. J. Landolt. 2013. Comparison of a synthetic chemical lure and standard fermented baits for trapping Drosophila suzukii (Dipetera: Drosophilidae). Environ. Entomol. 42: 1052-1060.

Cha, D. H., T. Adams, C. T. Werle, B. J. Sampson, J. J. Adamczyk, H. Rogg, and P. J. Landolt. 2014. A four-component synthetic attractant for Drosophila suzukii (Diptera: Drosophilidae) isolated from fermented bait headspace. Pest Manage. Sci. 70: 324-331.

Cini, A., C. Ioriatti, and G. Anfora. 2012. A review of the invasion of Drosophila suzukii in Europe and a draft research agenda for integrated pest management. B. Insectol. 65: $149-160$.

Demchak, K., D. Biddinger, and A. Surcică. 2012. Spotted wing drosophila. Part 1: Overview and identification. Penn State Extension. (http://pubs.cas.psu.edu/FreePubs/PDFs/ xj0045.pdf). Last accessed 6 March 2015.

Depra, M., J. L. Poppe, H. J. Schmitz, D. C. De Toni, and V.L.S. Valente. 2014. The first records of the invasive pest Drosophila suzukii in the South American continent. J. Pest Sci. 87: 379-383

Fleischer, S. J., C. L. Harding, P. E. Blom, J. White, and J. Grehan. 2005. Spodoptera frugiperda pheromone lures to avoid nontarget captures of Leucania phragmatidicola. J. Econ. Entomol. 98: 66-71.

Goodhue, R. E., M. Bolda, D. Farnsworth, J. C. Williams, and F. G. Zalom. 2011. Spotted wing drosophila infestation of California strawberries and raspberries: economic analysis of potential revenue losses and control costs. Pest Manage. Sci. 67: 1396-1402

Grassi, A., G. Anfora, S. Maistri, G. Maddalena, A. De Cristofaro, G. Savini, and C. Ioriatti. 2014. Development and efficacy of Droskidrink, a food bait for trapping Drosophila suzukii. In: IOBC VIII Workshop on Integrated Soft Fruit Production. 26-28 May 2014, Vigalzano di Pergine, Italy.

Haviland, D. R., and E. H. Beers. 2012. Chemical control programs for Drosophila suzukii that comply with international limitations of pesticide residues for exported sweet cherries. J. Integr. Pest Manage. 3: F1-F6.
Iglesias, L. E., T. W. Nyoike, and O. E. Liburd. 2014. Effect of trap design, bait type, and age on captures of Drosophila suzukii (Diptera: Drosophilidae) in berry crops. J. Econ. Entomol. 107: 1508-1518.

Landolt, P. J., T. Adams, and H. Rogg. 2012a. Trapping spotted wing drosophila, Drosophila suzukii (Matsumura) (Diptera: Drosophilidae), with combinations of vinegar and wine, and acetic acid and ethanol. J. Appl. Entomol. 136: 148-154.

Landolt, P. J., T. Adams, T. S. Davis, and H. Rogg. 2012 b. Spotted wing drosophila, Drosophila suzukii (Diptera: Drosophilidae), trapped with combinations of wines and vinegars Fla. Entomol. 95: 326-332

Lee, J. C., D. J. Bruck, H. Curry, D. Edwards, D. R. Haviland, R. A. Van Steenwyk, and B. M. Yorgey. 2011. The susceptibility of small fruits and cherries to spotted wing drosophila, Drosophila suzukii. Pest Manage. Sci. 67: $1358-1367$.

Lee, J. C., H. J. Burrack, L. D. Barrantes, E. H. Beers, A. J. Dreves, K. Hamby, D. R. Haviland, R. Isaacs, T. Richardson, P. Shearer, et al. 2012. Evaluation of Monitoring Traps for Drosophila suzukii (Diptera: Drosophilidae) in North America. J. Econ. Entomol. 105: 1350-1357.

Lee, J. C., P. W. Shearer, L. D. Barrantes, E. H. Beers, H. J. Burrack, D. T. Dalton, A. J. Dreves, L. J. Gut, K. A. Hamby, D. R. Haviland, et al. 2013. Trap designs for monitoring Drosophila suzukii (Diptera: Drosophilidae). Environ. Entomol. 42: 1123-1453.

Leskey, T. C., B. D. Short, B. R. Butler, and S. E. Wright. 2012. Impact of the invasive brown marmorated stink bug, Halyomorpha halys (Stål), in mid-Atlantic tree fruit orchards in the United States: case studies of commercial management. Psyche 2012: 1-14.

Roubos, C. R., C. Rodriguez-Saona, and R. Isaacs. 2014. Mitigating the effects of insecticides on arthropod biological control at field and landscape studies. Biol. Control 75: $28-38$.

Sakai, A. N., F. W. Allendorf, J. S. Holt, D. M. Lodge, J. Molofsky, K. A. With, S. Baughman, R. J. Cabin, J. E. Cohen, N. C. Ellstrand, et al. 2001. The population biology of invasive species. Ann. Rev. Ecol. Syst. 32: 305-332.

Tochen, S., D. T. Dalton, N. Wiman, C. Hamm, P. W. Shearer, and V. M. Walton. 2014. Temperature-related development and population parameters for Drosophila suzukii (Diptera: Drosophilidae) on cherry and blueberry. Environ. Entomol. 43: 501-510.

Utrio, P., and K. Eriksson. 1977. Volatile fermentation products as attractants for Macrolepidoptera. Ann. Zool. Fenn. 14: 98-104.

Van Timmeren, S., and R. Isaacs. 2013. Control of spotted wing drosophila, Drosophila suzukii, by specific insecticides and by conventional and organic crop protection programs. Crop Prot. 54: 126-133.

Walsh, D. B., M. P. Bolda, R. E. Goodhue, A. J. Dreves, J. Lee, D. J. Bruck, V. M. Walton, S. D. O'Neal, and F. G. Zalom. 2010. Drosophila suzukii (Diptera: Drosophilidae): invasive pest of ripening soft fruit expanding its geographic range and damage potential. J. Integr. Pest Manage. 106: 289-295.

Weber, D. C., and D. N. Ferro. 1991. Nontarget noctuids complicate integrated pest management monitoring of sweet corn with pheromone traps in Massachusetts. J. Econ. Entomol. 84: 1364-1369.

Received 17 September 2014; accepted 5 February 2015. 